\title{
STUDIES ON JET PENETRATION AND KERF WIDTH AT VARIOUS OPERATING PRESSURE IN MACHINING OF D2 HEAT TREATED STEEL USING ABRASIVE WATER JET
}

\author{
Deepak $D^{1}$, Akash $V^{2}$, Anjaiah $D^{3}$

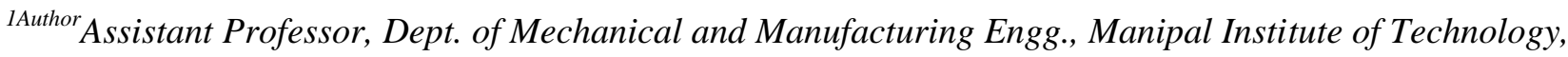 \\ Manipal University, Manipal, Karnataka state, India.email: nie.deepak@gmail.com \\ ${ }^{2}$ Student, Dept. of Mechanical and Manufacturing Engg., Manipal Institute of Technology, Manipal University, \\ Manipal, Karnataka state, India \\ 3Corresponding Author Professor, Dept. of Mechanical and Manufacturing Engg., Manipal Institute of Technology, Manipal \\ University, Manipal, Karnataka state, India.email:anjaiah.d@manipal.edu
}

\begin{abstract}
Abrasive Water Jet (AWJ) machining is one of the non-traditional machining method popular method for machining of hard, heat sensitive and brittle materials. The present work attempts to investigate the effect of operating pressure on depth of penetration and kerf characteristics generated while machining of D2 heat treated steel. It is found that increase in operating pressure increases the depth of penetration and decreases the surface taper on the work-piece.
\end{abstract}

Keywords: Kerf width, Depth of cut, Operating pressure, AWJ Machining *** $*$

\section{INTRODUCTION}

D2 steel is an air hardened, high-carbon, high-chromium tool steel, generally used in tool and die making applications. It has high wear and abrasion resistant properties. Because of the high carbon content D2 steel when heat-treated develops hardness up to a range of 60 - 65 HRC. Addition of chromium as an alloying element enhances the corrosion resistance properties in the hardened condition when compared to the conventional materials. Machining of such material by traditional machining methods is challenging due its high hardness. Machining industries are more sensitive with regard to quality and productivity of machining process. There are varieties of non-conventional machining processes such as Electric Discharge Machining, Chemical Machining, Laser Machining, AWJ machining, etc., The suitability of machining process depends on material properties and precision of machining. AWJ machining is one of the nontraditional machining method which is generally insensitive to material properties (Folkes, 2009). In abrasive water machining mixture of abrasive such as garnet, silicon carbide, etc., and water is directed on the target material. Erosion takes place due to rapid and repetitive action of the AWJ jet.

There have been cited literatures with regards to the effect of process parameters on performance of AWJ machining. From work of Momber (1998) and Hashish (1982), Kovacevic et. al. (1997), Kantha Babu et. al. (2002) and Srinivasu et. al. (2009), Deepak et al (2015) that the operating pressure, feed rate and standoff distance are the significant process parameters which influence the AWJ machining performance parameters such as material removal rate, kerf geometry and surface roughness. Khan et. al. (2007) studied the machining performance of various types of abrasive particles used in AWJ machining which revealed that silicon carbide abrasive particles exhibited better machining performance followed by aluminum oxide and garnet materials. Boud et. al. (2010) investigated the influence of abrasive morphology on machining of a titanium alloy, it was found that irregular shaped abrasive particles led to higher material removal and spherical shaped abrasive particles produced better surface finish. Chithirai et. al. (2011) and Wang (2007) investigated the effect of process parameters on the responses for machining of copper and alumina ceramics materials and developed response prediction models. Similar study was also conducted by Farhad et. al. (2009) on 6063-T6 Al alloy. Shanmugam et. al. (2008) found that kerf compensation techniques can substantially reduce the surface taper produced on alumina ceramics. Deepak et al (2014) studied the effect of standoff distance and feed rate as well as multipass machining on kerf width and surface roughness on D2 material. Although there have been cited literatures on the machining of various materials such as aluminum, brass, titanium, steel and tool steel were reported, there is a need to study the effect of operating parameters on machining of D2 steel material using AWJ. Hence, the present work aims at investigating the effect of operating pressure on depth of cut and kerf width as well as kerf taper. 


\section{MATERIALS AND METHODS}

\subsection{Experimental Setup}

Figure 1 shows the 3-axis AWJ machine used for conducting experimental work. The AWJ machine consists of an intensifier pump that generates high pressure water, abrasive feeding system and a cutting head which generates AWJ by abrasive injection. The movement of the cutting head on the work piece is controlled by computer numerical control system. The eroded material during machining is collected at catcher tank in which the remaining energy of the spent jet gets dissipated.

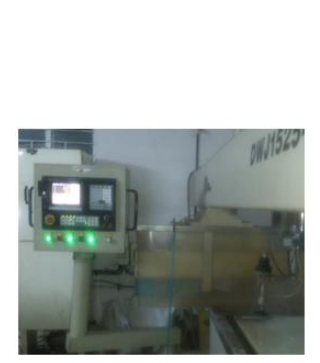

CNC control system

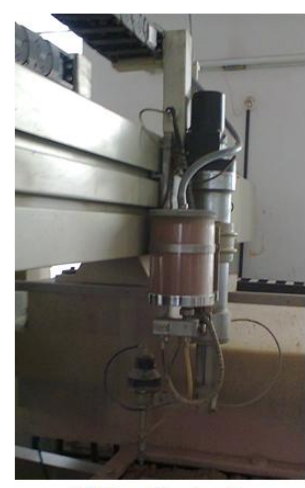

CNC cutting head
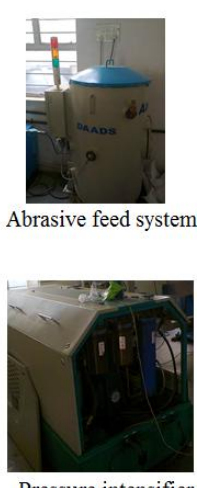

Pressure intensifier
Fig. 1 Experimental set up (Deepak et al, 2015)

\subsection{Work Material and Experimental Plan}

AISI D2 steel specimen is a high-carbon, high-chromium cold work steel. The average hardness of the test specimen is found to be 58 HRC. Work-piece was procured after the heat treatment process. Since the material exhibits high wear and abrasion resistant properties, it is used for manufacturing of tool and die. The experimental investigation has been carried out to find the effect of operating pressure on depth of cut, kerf width and kerf taper when machining with AWJ. The experiments were conducted on a test specimen of $8 \mathrm{~mm}$ thick, by keeping the standoff distance, feed rate and abrasive flow rate at constant settings. Abrasive used is Garnet ( $80 \mathrm{mesh}$ ) and the nozzle diameter is $0.76 \mathrm{~mm}$. Machining has been done by traversing the AWJ at single pass on the test specimen for a distance of $30 \mathrm{~mm}$. Response parameters such as kerf width and depth of penetrations were measured.

\section{RESULTS AND DISCUSSION}

\subsection{Effect of Operating Pressure on Depth of Cut}

Experiments were carried out at stand of distance of 1.23 $\mathrm{mm}$ and abrasive flow rate of $330 \mathrm{gm} / \mathrm{min}$. The operating pressure of the water is varied from $140 \mathrm{MPa}$ to $240 \mathrm{MPa}$. Figure 2 shows the upper, lower and front surface of the work piece that was machined at various jet pressure. It is seen that at lower pressures, the jet has not completely penetrated through the work piece. Through cut on the work piece is seen at operating pressure $216 \mathrm{MPa}$ and $240 \mathrm{MPa}$.

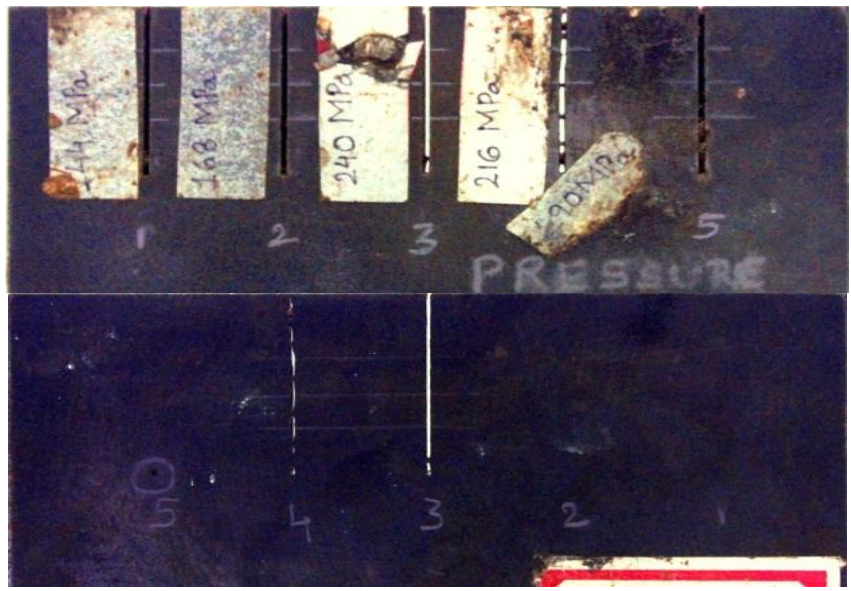

Fig. 2 Workpieces at various jet pressure

Figure 3 shows the depth of jet penetration on work-piece at various operating pressures. It is observed that the depth of jet penetration increases almost linearly with increase in the operating pressure. At lower pressures the impact of the AWJ on the material is not sufficient to remove more material. It is found by Deepak et. al. (2012) that increase in the operating pressure increases the jet kinetic energy. Thus the abrasive particles are forced at a greater force against the work piece leading to increase in depth of penetration.

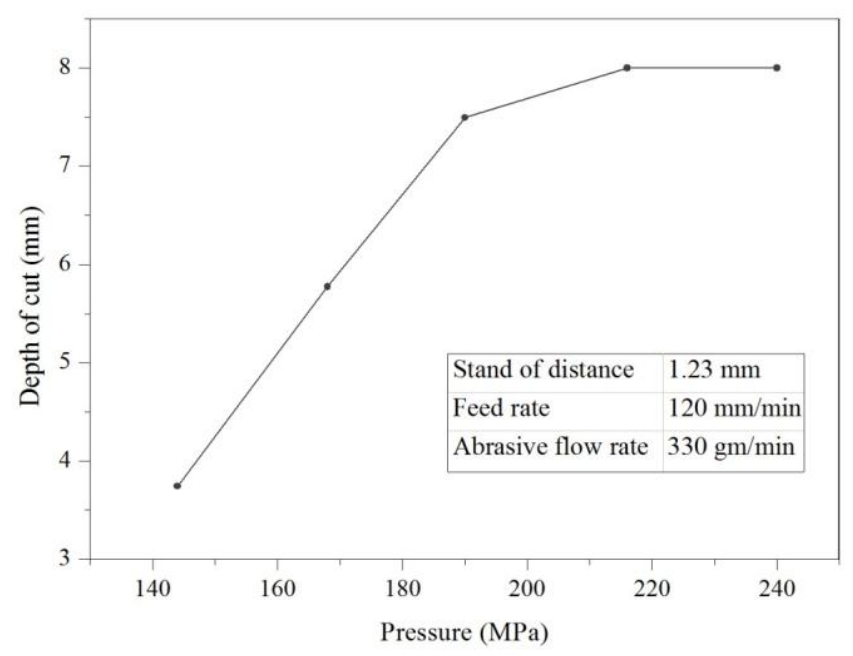

Fig. 3 Depth of cut at different jet pressure

\subsection{Effect of Operating Pressure on Kerf Width}

The top and bottom kerf width generated on the work piece at different operating pressure is shown in Figure 4. It is observed that there is slight increase in the top kerf width for an increase in the pressure. This is due to the fact that, the diameter of the jet increases with increase in operating pressure resulting in increase of kerf width. At lower operating pressure, since the AWJ could not penetrate through the workpiece completely, the bottom kerf width couldnot be measured. Through cut is observed that at operating pressure $216 \mathrm{MPa}$ to $240 \mathrm{MPa}$ due to higher jet kinetic energy. However, top kerf width is found to be wider than the bottom width in each experiment. For this reason the machined side walls exibhit tapered sufaces as shown in Figure 5. The surface taper produced on the 
workpiece at various operating pressure is also shown in Figure 6. The jet impacts on the top surface with higher jet kinetic energy. As the jet proceeds further inside the workpiece, the kinetic energy of the jet reduces due to jet turbulence. Hence the smaller kerf width is observed at the lower surface.

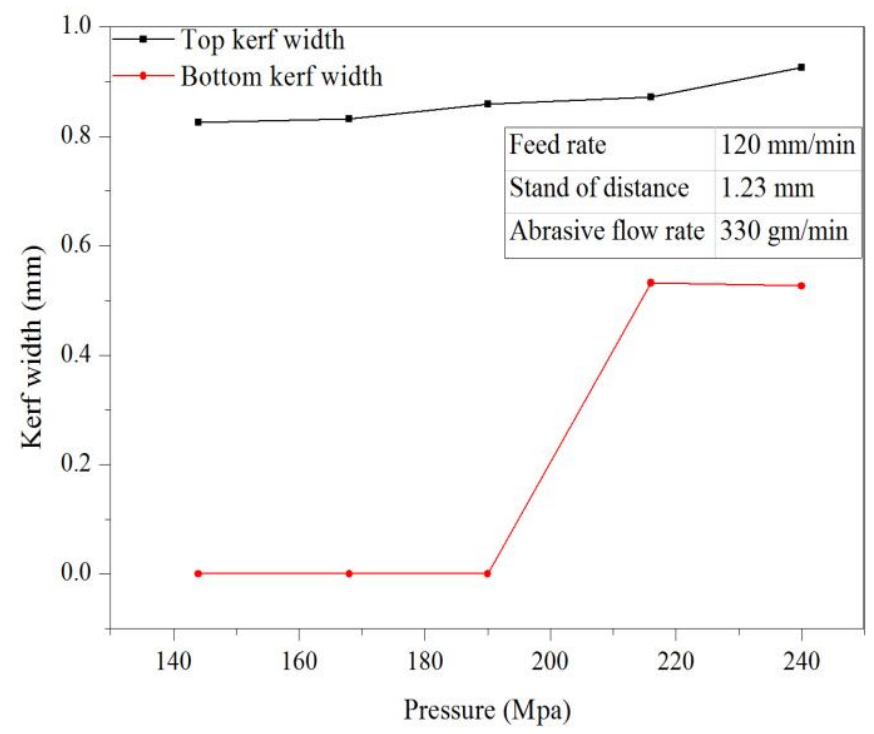

Fig 4 Kerf width at different jet pressure

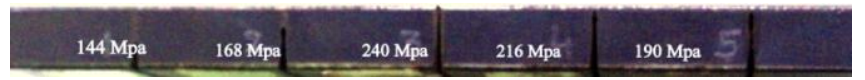

Fig 5 Kerf taper on workpiece

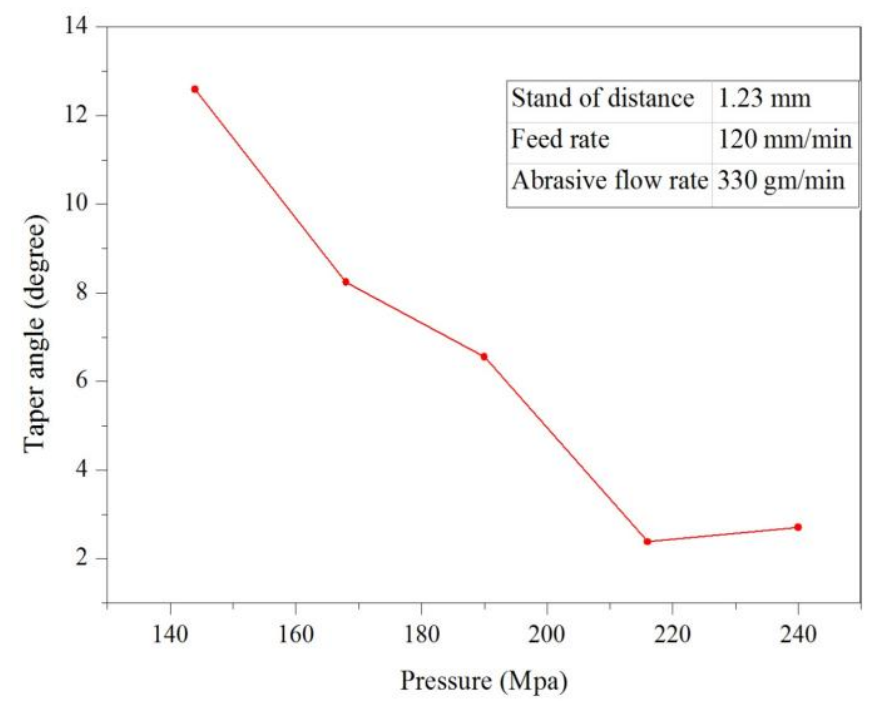

Fig 6 Plot of taper angle at different pressure pressure

\section{Conclusion}

Following conclusions are drawn from the present experimental work with regard to machining of D2 grade heat treated steel of a chosen thickness. The depth of cut on work piece increases linearly with increase in jet operating pressure. At pressure of $240 \mathrm{MPa}$ the kerf taper produced on the work piece is close to $2.1^{0}$. The kerf taper decreases with increase in the jet operating pressure.

\section{REFERENCES}

[1]. Andreas W Momber and Radovan Kovacevic, "Principles of Abrasive Water Jet Machining", Spinger-Verlag London limited, 1998, ISBN 3-54076239-6.

[2]. Boud F, Carpenter C, Folkes, J, Shipway, P. H, "Abrasive waterjet cutting of a titanium alloy: The influence of abrasive morphology", Journal of Materials Processing Technology, Volume 210, Issue 15, 2010, pp. 2197-2205.

[3]. Chithirai Pon Selvan M, Dr. N. Mohana Sundara Raju., "Selection of process parameters in abrasive waterjet cutting of copper", International Journal of Advanced Engineering Sciences and Technologies, vol 7,issue 2: pp 254-257, 2011.

[4]. Deepak Doreswamy., V Akash, Winitthumkul Natt, Anjaiah Devineni, "Machining of d2 heat treated steel using abrasive water jet : the effect of standoff distance and feed rate on kerf width and surface roughness", International Journal of Research in Engineering and Technology, vol 3 (8), pp. 417-421, 2014.

[5]. Deepak Doreswamy, B Shivamurthy, Devineni Anjaiah, N. Yagnesh Sharma, "An investigation of Abrasive Water Jet Machining on Graphite/Glass/Epoxy Composite", International Journal of Manufacturing Engineering, vol - 2015, 2015, doi:10.1155/2015/627218

[6]. Deepak Doreswamy, K V Karanth, Devineni Anjaiah, N. Yagnesh Sharma, "CFD Simulation of Flow in an Abrasive Water Suspension Jet the Effect of Inlet operating Pressure and Volume Fraction on Skin Friction and Exit Kinetic Energy", Advances in Mechanical Engineering, vol - 2012, 2012 doi:10.1155/2012/18643020.

[7]. Folkes, J, "Waterjet - An innovative tool for manufacturing", Journal of Materials Processing Technology, Volume 209, 2009, pp. 6181-6189.

[8]. Farhad Kolahan, Hamid Khajavi A. "A statistical approach for predicting and optimizing depth of cut in AWJ machining for 6063-T6 Al alloy". World Academy of Science, Engineering and Technology 59, 2009.

[9]. M. Hashish, "Steel Cutting with Abrasive Waterjets," presented at 6th International Symposium on Jet Cutting Technology, University of Surrey, U.K., BHRA Fluid Engg., 1982.

[10].M. Kantha Babu and O. V. K. Chetty, “Abrasive Water Jet Machining of Black Granite with Garnet Abrasives," Journal of The Institution of Engineers (India), Mechanical Engineering Division, vol. 83, pp. 7-14, Sep 2002.

[11]. Khan A.A. and M.M. Haque, "Performance of different abrasive materials during AWJM of glass", Journal of Materials Processing Technology, vol. 191, 2007, pp. 404-407.

[12]. R. Kovacevic, M. Hashish, R. Mohan, M. Ramulu, T. J. Kim, and E. S. Geskin, "State of the Art of Research and Development in Abrasive Waterjet Machining," Transactions of the ASME, Journal of Manufacturing 
Science and Engg, vol.119, pp. 776- 785, Nov 1997.

[13]. Shanmugam D. K., Wang J., Liu H. "Minimization of kerf tapers in abrasive waterjet machining of alumina ceramics using a compensation technique", International Journal of Machine Tools and Manufacture 48: pp 1527-1534, 2008.

[14]. Srinivasu, Axinte, P.H. Shipway, J. Folkes, "Influence of kinematic operating parameters on kerf geometry in abrasive waterjet machining of silicon carbide ceramics", International Journal of Machine Tools and Manufacture, Vol.49, Issue 14, pp. 1077-1088, 2009.

[15]. Wang J. "Predictive depth of jet penetration models for abrasive waterjet cutting of alumina ceramics". International Journal of Mechanical Sciences 49: pp 306-316, 2007. 